\title{
Film boiling heat transfer for saturated drops impinging on a heating surface
}

\author{
SHIGEAKI INADA \\ Department of Mechanıcal System Engineering, Gunma University, Kiryu 376, Japan \\ and \\ WEN-JEI YANG $\dagger$ \\ Department of Mechanical Engineering and Applied Mechanics, University of Michigan, Ann Arbor, \\ MI 48109-2125. U.S.A.
}

(Received 16 March 1993 and in final form 28 February 1994)

\section{INTRODUCTION}

FILM boiling of liquid drops in contact with a heating surface can be found in combustion inside a fuel injection engine, spray cooling of a heating surface, mist flow inside a heating tube and vapor explosion at liquid-liquid contact. In general, heat transfer performance in the liquid-drop system is superior to that in pool boiling, and is thus characterized by broad applications. However, its mechanism is not well understood, since the dynamic behavior and transient heat transfer of drops are clearly interrelated. For example, to determine the heat transfer rate between a drop and a heating surface, it is necessary to determine the timewise variations of both the drop spreading area and vapor layer thickness, the vapor flow velocity and the effects of the impinging Weber number, drop diameter and wall superheat on the heat transfer rate.

The experimental studies on film boiling of drops include Wachters et al. [1], Pedersen [2], Ueda et al. [3] and Shoji $c t$ al. [4]. They determined drop heat transfer effectiveness, not from the measurement of heat transfer coefficients, but from the timewise variations in both the temperature and heat capacity of the heating surface following drop impingement. By approximating drop shape as a circular cylinder and a hemisphere, Kendall and Rohsenow [5] conducted heat transfer analysis taking into account both the motion due to drop deformation and the motion of the drop's gravitational center. They determined the radius of the spreading drop, vapor layer thickness, timewise variations in heat fluxes and the effects of the drop diameter, wall superheat and impinging Weber number on heat transfer effectivenes. The assumed drop geometry produced little difference in analytical results. No attempt was made to derive a dimensionless correlation equation indicating the effects of each governing parameter on heat transfer performance (i.e. Nusselt number). Hence, results for film boiling heat transfer of an impinging drop system (Kendall and Rohsenow [5]) are not applicable to broad ranges of the governing parameters.

The present study derives a dimensionless correlation equation for film boiling heat transfer of an impinging drop system, as a function of the Weher number related to the impinging velocity of a drop, Bond number, Prandt number and a new parameter, that is, the Weber number related to the vapor stream, through an analytical investigation of five

† Author to whom correspondence should be addressed. liquids with distinct physical properties. Results are compared with the empirical correlation equation for forced convection film boiling over a circular cylinder (Bromley et al. [6]) to determine the range of its applicability to the present drop boiling system.

\section{THEORETICAL ANALYSIS}

Consider a vapor layer enclosed between a drop base and a heating surface, as shown in Fig. 1. The cylindrical coordinate system $(r, z)$ is employed with the origin fixed at the center of the drop base. The coordinates $r$ and $z$ measure the radial and axial distance, respectively, $u_{r}$ and $u_{z}$, respectively, denote the velocity components in the $r$ and $z$ directions. $T$ represents the stream temperature. The conservation equations then read:

continuity equation :

$$
\frac{\partial u_{r}}{\partial r}+\frac{u_{r}}{r}+\frac{\partial u_{z}}{\partial z}=0
$$

momentum equation in the $r$ direction :

$$
\rho_{\mathrm{g}}\left(u_{r} \frac{\partial u_{r}}{\partial r}+u_{2} \frac{\partial u_{r}}{\partial z}\right)=-\frac{\partial P}{\partial r}+\mu_{\mathrm{g}} \frac{\partial^{2} u_{r}}{\partial z^{2}}
$$

energy equation :

$$
u_{r} \frac{\partial T}{\partial r}+u_{z} \frac{\partial T}{\partial z}=a_{\mathrm{z}} \frac{\partial^{2} T}{\partial z^{2}}
$$

The appropriate boundary conditions are :

at $z=0$ :

$$
u_{r}=0, \quad u_{z}=0, \quad T=T_{\mathrm{w0},}, \quad \partial^{2} T / \partial z^{2}=0
$$

at $z=z_{\mathrm{b}}$ :

$$
u_{r}=U_{r}, \quad u_{z}=-U_{0}, \quad T=T_{\mathrm{s}}, \partial T / \partial z=-\beta_{2}\left(T_{\mathrm{w} \theta}-T_{\mathrm{s}}\right) / z_{\mathrm{b}} .
$$

Here, $U$, denotes the radial flow velocity within the drop (expressed by equation (16)) and $U_{0}$ is the vapor ejection velocity at the drop base whose vertical translation velocity is taken into account. $z_{\mathrm{t}}$ represents the vapor layer thickness $\left(z_{\mathrm{b}}=z_{\mathrm{c}}-W / 2\right)$ and $\beta_{2}$ is a nonlinear temperature distribution coefficient inside the vapor layer. After all the factors, $\beta_{1}$ and $\beta_{2}$ are introduced to account for the non- 


\section{NOMENCLATURE}

\begin{tabular}{|c|c|}
\hline$a_{\mathrm{g}}$ & thermal diffusitivity $\left[\mathrm{m}^{2} \mathrm{~s}^{-i}\right]$ \\
\hline Bo & Bond number, $g\left(\rho_{\mathrm{f}}-\rho_{\mathrm{g}}\right) D^{2} / \sigma$ \\
\hline$D$ & drop diameter [m] \\
\hline$D_{3}$ & horizontal tube diameter [m] \\
\hline$F$ & force defined by equation (ll) [N] \\
\hline$g$ & gravitational acceleration $\left[\mathrm{m} \mathrm{s}^{-2}\right]$ \\
\hline$I_{1}, I_{2}$ & $\begin{array}{l}\text { dimensionless parameters defined by } \\
\text { equation (12) }\end{array}$ \\
\hline$L_{\mathrm{g}}$ & latent heat of vaporization $\left[\mathrm{kJ} \mathrm{kg}^{-1}\right]$ \\
\hline $\mathrm{Nu}$ & Nusselt number \\
\hline$P$ & Prandti number of liquid drop \\
\hline$Q_{u}$ & heat flow rate to drop $[\mathrm{W}]$ \\
\hline$q$ & $\begin{array}{l}\text { heat flux }\left[\mathrm{W} \mathrm{m}^{-2}\right] ; q_{w} \text { at heating surface: } \\
q_{\mathrm{cv}} \text { at drop base }\end{array}$ \\
\hline$R$ & radius of drop base $[\mathrm{m}]$ \\
\hline$r$ & radial coordinate $[\mathrm{m}]$ \\
\hline$S_{\mathrm{c}}$ & spreading area of drop base $\left[\mathrm{m}^{2}\right]$ \\
\hline$T$ & temperature $[\mathrm{C}]$ \\
\hline$T_{\mathrm{h}}$ & Weber number for vapor stream \\
\hline$T_{\mathrm{s}}$ & saturation temperature $[\mathrm{C}]$ \\
\hline$T_{\mathrm{w} 0}$ & heating surface temperature $[\mathrm{C}]$ \\
\hline$U_{\mathrm{a}}$ & steam ejection velocity at drop base $\left[\mathrm{m} \mathrm{s}^{-1}\right]$ \\
\hline$U_{\mathrm{b}}$ & velocity of drop base $\left[\mathrm{m} \mathrm{s}^{-1}\right]$ \\
\hline$U_{0}$ & $\begin{array}{l}\text { net steam velocity at drop base, } U_{\mathrm{a}}-U_{\mathrm{n}} \\
{\left[\mathrm{m} \mathrm{s}^{-1}\right]}\end{array}$ \\
\hline$u$ & $\begin{array}{l}\text { steam velocity }\left[\mathrm{m} \mathrm{s}^{-1}\right] ; u_{r} \text { and } u_{z} \text { in the } r \\
\text { and } z \text { directions, respectively }\end{array}$ \\
\hline$u_{\mathrm{s}}$ & $\begin{array}{l}\text { flow velocity crossed the horizontal tube } \\
{\left[\mathrm{m} \mathrm{s}^{-1}\right]}\end{array}$ \\
\hline $\begin{array}{l}V_{0} \\
W\end{array}$ & $\begin{array}{l}\text { fall velocity of liquid drop }\left[\mathrm{m} \mathrm{s}^{-1}\right] \\
\text { drop height }[\mathrm{m}] ; W_{0} \text {, initial height }\end{array}$ \\
\hline
\end{tabular}

\author{
$W_{t^{2}} \quad$ Weber number \\ $Z_{0} \quad$ initial height of drops gravitational center \\ [m] \\ $z \quad$ axial coordinate $[\mathrm{m}] ; z_{\mathrm{b}}$ of drop base; $z_{c}$ of \\ drop gravitational center.
}

Greek symbols

$\alpha$ heat transfer coefficient for drop impinging film boiling $\left[\mathrm{W} \mathrm{m}^{-2} \mathrm{~K}^{-1}\right]$

$x_{i n} \quad$ heat transfer coefficient for forced

convection film boiling [ $\mathrm{W} \mathrm{m}^{-2} \mathrm{~K}^{-1}$ ]

$\beta \quad$ nonlinear temperature distribution coefficient; $\beta_{1}$ at heated surface inside vapor layer; $\beta_{2}$ at drop base inside vapor layer

$\Delta T_{\text {bil }} \quad$ wall superheat, $T_{\mathrm{wif}}-T_{\mathrm{s}}[\mathrm{K}]$

$\lambda_{\mathrm{g}} \quad$ thermal conductivity $\left[\mathrm{W} \mathrm{m}^{-1} \mathrm{~K}^{-1}\right]$

$\mu_{\mathrm{g}} \quad$ viscosity [Pa s]

$v_{g} \quad$ kinematic viscosity $\left[\mathrm{m}^{2} \mathrm{~s}^{-1}\right]$

$\rho_{g} \quad$ density $\left[\mathrm{kg} \mathrm{m}^{-3}\right]$

$\sigma \quad$ surface tension $\left[\mathrm{N} \mathrm{m}^{-1}\right]$

$\tau \quad$ lime $[\mathrm{s}]$

$\tau_{\mathrm{c}} \quad$ effective heat transfer time [s]

$\tau_{\mathrm{r}} \quad$ freely oscillating period of a liquid drop [s].

Subscripts

$f$ liquid phase

g steam

0 initial value.

Superscript

time averaged value. linearity in the temperature distribution, so that the heat flux removed from the wall is :

$$
q_{\mathrm{w}}=\beta_{1} \hat{\lambda}_{\mathrm{g}}\left(T_{\mathrm{w} 0}-T_{\mathrm{s}}\right) / z_{\mathrm{b}}
$$

and the heat flux transferred to the drop base is :

$$
q_{\mathrm{wr}}=\beta_{2} \lambda_{\mathrm{g}}\left(T_{\mathrm{w} 0}-T_{\mathrm{s}}\right) / z_{\mathrm{b}} .
$$

Here, $\lambda_{\mathrm{g}}$ denotes the thermal conductivity of the vapor; $T_{\mathrm{wo}}$ is the heating surface temperature, and $T$, is the saturation temperature.

If the boundary condition, $\partial T / \partial z=-\beta_{1}\left(T_{\mathrm{w} 0}-T_{\mathrm{s}}\right) / z_{\mathrm{b}}$ at $z=0$ is applied, $\beta_{1}$ and $\beta_{2}$ can be related by

$$
2 \beta_{1}+\beta_{2}=3
$$

where $\beta_{1}$ and $\beta_{2}$ are still unknown. These factors are determined by integrating equation (3) with respect to $z$.

For simplicity in mathematical manipulation, it is assumed that at the moment of impingement on the heating surface, a spherical drop of diameter $D$ takes the form of a cylinder with radius $R$ and height $W$, as illustrated in Fig. 1. The drop then changes in shape on the heating surface under the condition of constant volume, with its height $W$ varying as a function of time $\tau$. Let the height of its gravitational center be $z_{\mathfrak{c}}$. Then we can derive an equation for drop deformation based on the internal flow as

$$
\begin{array}{r}
\frac{\mathrm{d}^{2} W}{\mathrm{~d} \tau^{2}}=-\frac{6}{\pi D^{3} \rho_{\mathrm{f}}}\left[\frac{1}{2} F+2 \pi \sigma D\left(\frac{1}{2} \sqrt{\left.\left(\frac{D}{6 W}\right)-\frac{1}{6}\left(\frac{D}{W}\right)^{2}\right)}\right.\right. \\
\left.-\frac{\rho_{\mathrm{f}} \pi D^{3}}{32 D 6}\left(\frac{D}{W}\right)^{4}\left(\frac{\mathrm{d} W}{\mathrm{~d} \tau}\right)^{2}\right] /\left[\frac{1}{12}+\frac{1}{48}\left(\frac{D}{W}\right)^{3}\right]
\end{array}
$$

$$
\frac{\mathrm{d}^{2} z_{\mathrm{c}}}{\mathrm{d} \tau^{2}}=\frac{6 F}{\pi D^{3} \rho_{\mathrm{f}}}-g .
$$

Here, $\rho_{\mathrm{f}}, \sigma, g$ and $F$ denote the liquid density, surface tension, gravitational acceleration, and force acting on the drop base, respectively.

The force $F$ is induced by the pressure rise inside the superheated vapor layer formed between the drop base and the heating surface. The pressure rise results from the radial flow that overcomes the viscous force within the vapor layer and the accelerating flow in the radial direction out from between the drop and the wall. Hence, the force $F$ can be derived from the continuity and momentum equations of the

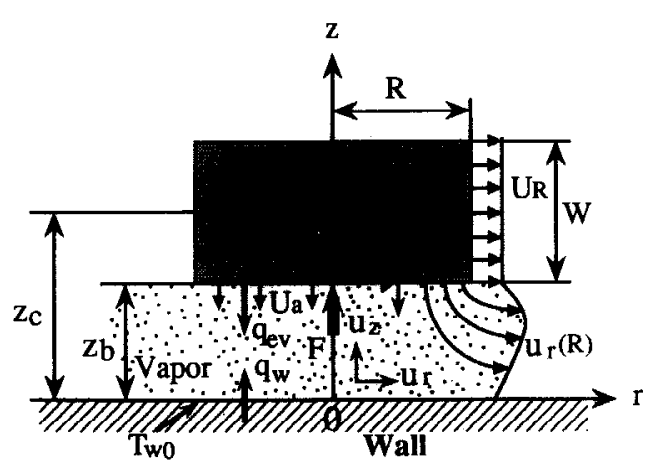

FIG. 1. Model of deforming drop and vapor flow. 
vapor layer as

$$
F=\frac{\pi R^{4}}{4}\left(\frac{\rho_{\mathrm{g}} U_{0}^{2}}{z_{\mathrm{b}}^{2}} I_{1}-\frac{\mu_{\mathrm{g}} U_{0}}{2 z_{\mathrm{b}}^{3}} I_{2}\right)
$$

where

$$
\begin{aligned}
& I_{1}=9 / 10+13 /\left(20\left(U_{\mathrm{w}} / U_{0}\right)\right)+1 /\left(10\left(U_{\mathrm{w}} / U_{0}\right)^{2}\right) \\
& I_{2}=-12-6\left(U_{\mathrm{w}} / U_{0}\right) .
\end{aligned}
$$

Here, $\rho_{y}$ and $\mu_{\mathrm{g}}$ are the density and viscosity of the superheated stream. respectively. $U_{n}$ represents the net vertical velocity of vapor at the drop base, and is the sum of the velocity of the drop base $U_{\mathrm{b}}$, and the vapor cjection velocity at the drop base $U_{\mathrm{a} 1}$. That is,

$$
\begin{gathered}
U_{\mathrm{a}}=\beta_{2} \lambda_{\mathrm{g}} \Delta T_{\mathrm{sut}} /\left(\rho_{\mathrm{g}} L_{\mathrm{g}} z_{\mathrm{h}}\right) \\
U_{\mathrm{b}}=\mathrm{d}_{z_{\mathrm{c}}} \mathrm{d} \tau-1 / 2(\mathrm{~d} W / \mathrm{d} \tau) \\
U_{0}=U_{\mathrm{a}}+\left(-U_{\mathrm{h}}\right) \\
U_{r}=(-1 / 2)\left(U_{\mathrm{w}} / z_{\mathrm{b}}\right) r \\
U_{\mathrm{u}}=(\mathrm{d} W / \mathrm{d} \tau)\left(z_{\mathrm{b}} / W\right)
\end{gathered}
$$

where $L_{\mathrm{g}}$ represents the latent heat of evaporation and $\Delta T_{\text {valt }}=T_{\mathrm{w}(1)}-T_{\text {s. }}$

The conservation equations (1)-(3) and the drop deformation equations $(9)$ and $(10)$ are coupled. The physical time is divided into small intervals. At each time interval, the coupled equations are integrated by means of the RungeKutta method.

The initial conditions are

$$
\begin{gathered}
\beta_{2}=1, \quad W=W_{0}=0.87 D, \quad \mathrm{~d} W / \mathrm{d} \tau=0 \\
z_{\mathrm{c}}=Z_{0}, \quad \mathrm{~d} z_{\mathrm{c}} / \mathrm{d} \tau=-V_{0} .
\end{gathered}
$$

Here, $Z_{0}$ is the initial height of the drop's gravitational center and may take an arbitrary value for which $z>W_{0} / 2 . V_{0}$ is the falling velocity of the drop.

The computational procedure is to first substitute the instantaneous values of $W$ and $z_{\mathrm{c}}$ obtained from equations (9) and (10) into the momentum equation (2) to determine $F$, followed by evaluating $\beta$, from the energy equation (3). In the next time instant, the Runge-Kutta method is employed to integrate equations (9) and (10).

\section{RESULTS AND DISCUSSION}

Results are obtained for various liquid drops of water, methanol, ethanol, butanol and propanol. Drop diameters vary in the range $0.22,1.0,2.3$ and $4.0 \mathrm{~mm}$, wall superheats in the range 200,400 and $600 \mathrm{~K}$, and Weber numbers for impinging drop in the range 12.3,25,50,100 and 300 The physical properties at the saturated film temperature $\left(T_{\mathrm{w} 0}+T_{\mathrm{s}}\right) / 2$ are employed in the numerical computations. The dimensionless parameters are defined as: Weber number for liquid drop, $W e=\rho_{\mathrm{f}} V_{0}^{2} D / \sigma$; Bond number, $B o=g\left(\rho_{\mathrm{f}}-\rho_{\mathrm{g}}\right) D^{2} / \sigma ;$ Weber number for vapor stream, that is, inertia force/surface tension force,

$$
T_{\mathrm{h}}=\left(\lambda_{\mathrm{g}} \Delta T_{\text {sut }} / L_{\mathrm{g}}\right) / \sqrt{ }\left(\rho_{\mathrm{g}} \sigma D\right)=\sqrt{ }\left(\rho_{\mathrm{g}} U_{\mathrm{a}}^{2} z_{\mathrm{b}}^{2}\right) / \sqrt{ }(\sigma D)
$$

where $U_{\mathrm{a}}$ is expressed by equation (13) with $\beta_{2}=1$.

Figure 2 is a typical result illustrating the time history of $q_{\mathrm{w}}$ for butanol drops of $D=4.0 \mathrm{~mm}$ and $\Delta T_{\text {sat }}=200 \mathrm{~K}$ The abscissa is the physical time non-dimensionalized by the freely oscillating period of a liquid drop $\tau_{r}$. It is obvious in Fig. 2 that $q_{w}$ reduces with an increase in Weber number. The heat flux $q_{\mathrm{w}}$ takes two to three maxima within the period. The time-averaged heat transfer performance (Nusselt number) is defined based on the time-averaged value of $q_{n}$ as

$$
N u=\bar{q}_{\mathrm{u}} /\left(\hat{\ell}_{\mathrm{g}} \Delta T_{\mathrm{st}} / D\right)
$$

where

$$
\begin{gathered}
\bar{q}_{\mathrm{w}}=\bar{Q}_{\mathrm{w}} / \overline{S_{\mathrm{c}}} \\
\bar{Q}_{\mathrm{w}}=\frac{1}{\tau_{\mathrm{c}}} \int_{0}^{\tau_{\mathrm{c}}} q_{\mathrm{w}} \pi R^{2} \mathrm{~d} \tau \\
\bar{S}_{\mathrm{c}}=\frac{1}{\tau_{\mathrm{c}}} \int_{0}^{\tau_{\mathrm{c}}} \pi R^{2} \mathrm{~d} \tau .
\end{gathered}
$$

$\tau_{L}$ signifies the effective heat transfer time. It is almost equal to the restoring period for an impinging drop, the time it takes to reach the original value $W_{0}, \bar{q}_{\mathrm{w}}$ reduces resulting from an enhancement in $\pi R^{2}$ (spreading area of the drop) in equation (22) as the Weber number is increased.

Figure 3 plots all data obtained in the present analysis. A correlation equation expressed by equation (23) is derived with a scattering range between $+50 \%$ and $-36 \%$

$$
\mathrm{Nu}=2.80 T_{\mathrm{h}}^{-0.56}(\mathrm{We} / 2+13)^{-0.56} \mathrm{Bo}^{-0.056} \mathrm{Pr}^{0.31}
$$

Here, $\operatorname{Pr}$ denotes the Prandtl number of the liquid. The effects of $\Delta T_{\text {xal }}, D$ and $W e$ on the heat transfer coefficient $x$ are derived from equation (23) as

$$
\alpha \propto \Delta T_{\mathrm{sat}}^{-0.56} D^{-0.832}(\mathrm{We} / 2+13)^{-0.56} .
$$

This shows that $\alpha$ is enhanced with a decrease in $\Delta T_{\text {sal }}, D$ and $W e$.

To the authors' knowledge, there are no experimental data to ascertain the validity of the present analysis (represented by equation (23)). However, it is of interest to compare film boiling of saturated drops impinging on a heating surface with forced convection film boiling from a horizontal tube (Bromley et al. [6]) whose correlation equation is

$$
\alpha_{\mathrm{co}} \sqrt{ }\left[D_{\mathrm{s}} \Delta T_{\mathrm{sat}} /\left(u_{\mathrm{s}} \lambda_{\mathrm{g}} \rho_{\mathrm{g}} L_{\mathrm{g}}\right)\right]=2.7
$$

where $\alpha_{c o}$ is the heat transfer for forced convection film boiling, $D_{\mathrm{s}}$ is the horizontal tube diameter and $u_{\mathrm{s}}$ is the flow velocity across the tube. Treating the tube diameter $D_{\mathrm{s}}$ as the drop diameter, and the flow velocity $u_{\mathrm{s}}$ as the velocity of a drop impinging on the heating surface, equation (25) can be rewritten in dimensionless form as

$$
N u=2.7 T_{\mathrm{h}}^{-0.5} W e^{0.25}\left(\rho_{\mathrm{g}} / \rho_{\mathrm{i}}\right)^{0.25}
$$

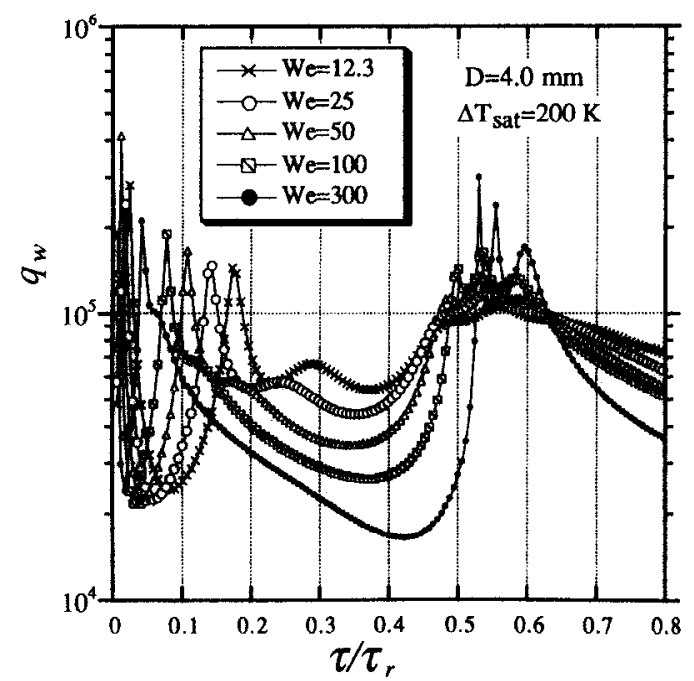

Fic. 2. Time history of heat flux for butanol drops. 


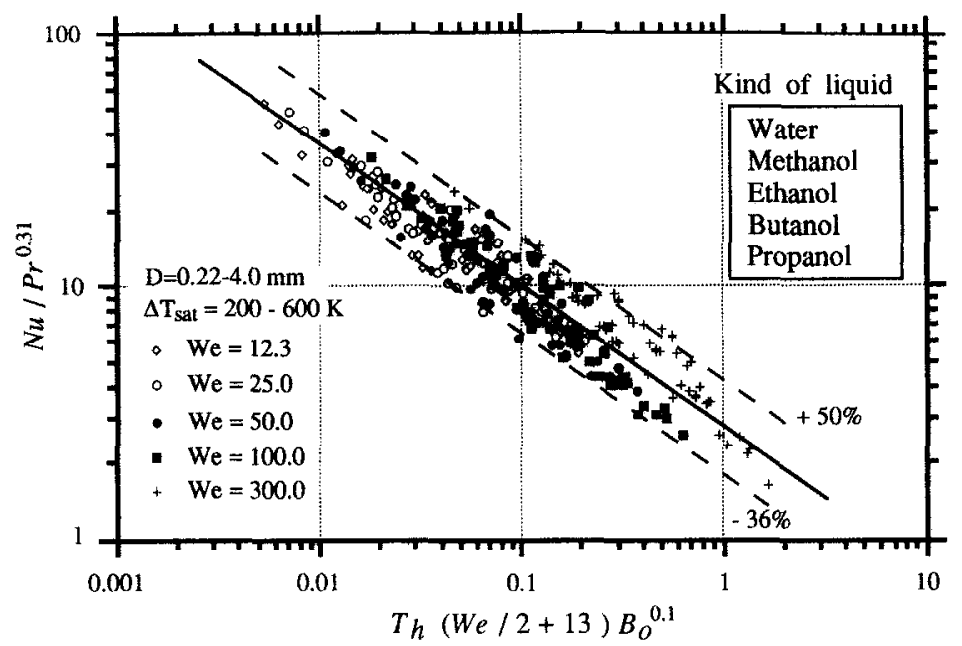

Fig. 3. A correlation of film boiling heat trąnsfer for saturated drops impinging on a heating surface.

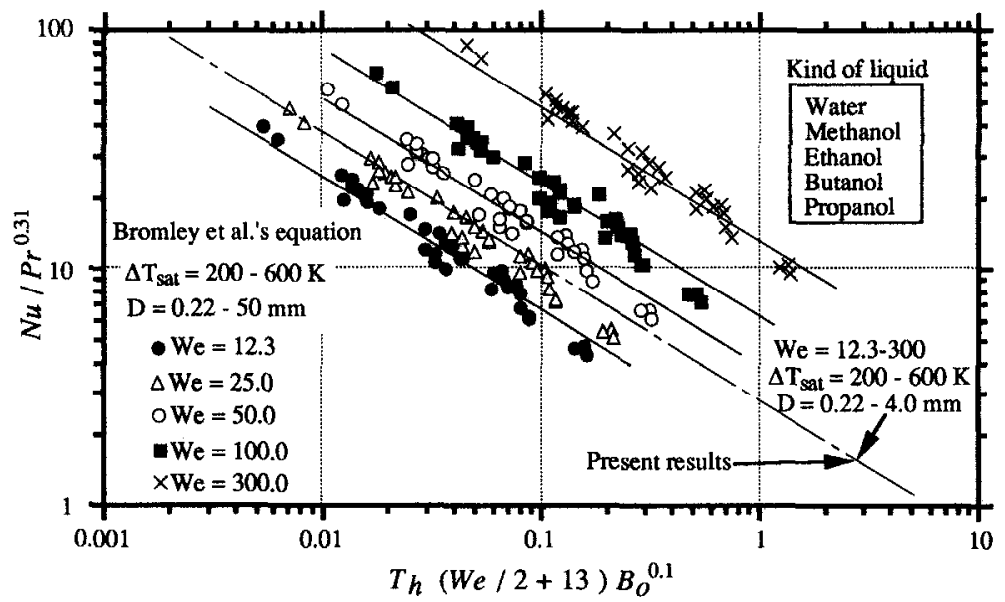

Figi. 4. Comparison of heat transfer between film boiling of saturated drops impinging on a heating surface and a forced convection film boiling over a horizontal tube.

Equation (26), together with test data of Bromley el al. [6]. are plotted in Fig. 4 for $D=0.22-50 \mathrm{~mm}, \Delta T_{\mathrm{stt}}=200-$ $600 \mathrm{~K}$, and $W e=12.3-300$. Equation (23) is superimposed as the chain line for comparison. It is seen that equations (23) and (26) have the same slope, and that equation (26) is applicable to film boiling of saturated drops impinging on a heating surface for Weber number in the range of 12.3-50.

\section{CONCLUSIONS}

A theoretical analysis has been conducted to determine film boiling heat transfer of saturated drops impinging on a heated surface, taking into account the dynamics of drop deformation. A new dimensionless parameter has been derived which relates conductive heat transfer through a vapor layer, and evaporation rate of the liquid induced by surface tension. It is conciuded from the study that the heat transfer performance of the drop film boiling system can be predicted by equation (23), and that the empirical correlation equation for forced convection film boiling over a circular cylinder, equation (26), can be applied to the drop film boiling system with the impinging Weber number between 12.3 and 50 .

\section{REFERENCES}

1. L. H. J. Wachters, L. Smulders, J. R. Vermeulen and H. C. Kleiweg, The heat transfer from a hot wall to impinging mist droplets in the spheroidal state, Chem. Engng Sci. 21, 1231-1238 (1966)

2. C. O. Pedersen, An experimental study of the dynamic behavior and heat transfer charactristics of water droplets impinging upon a heated surface, Int. J. Heat Mass Transfer 13, 369-381 (1970).

3. T. Ueda, T. Enomoto and M. Kanetsuki, Heat transfer characteristics and dynamic behavior of saturated droplets impinging on a heated vertical surface, Bull. JSME 22, 724-732 (1979).

4. M. Shoji, T. Wakunaga and K. Kodama, Heat transfer between subcooled impinging droplet and a heated surface (heat transfer characteristics in non-wetting region), Trans. JSME 50, 716-723 (1984).

5. G. E. Kendall and W. M. Rohsenow, Heat transfer to impacting drops and post critical heat flux dispersed flow. MIT, Tech. Rep. No. 85694-100 (March 1978).

6. L. A. Bromley, N. R. Leroy and J. A. Robbers, Heat transfer in forced convection film boiling, Industrial Engng Chem. 45, 2639-2646 (1953). 